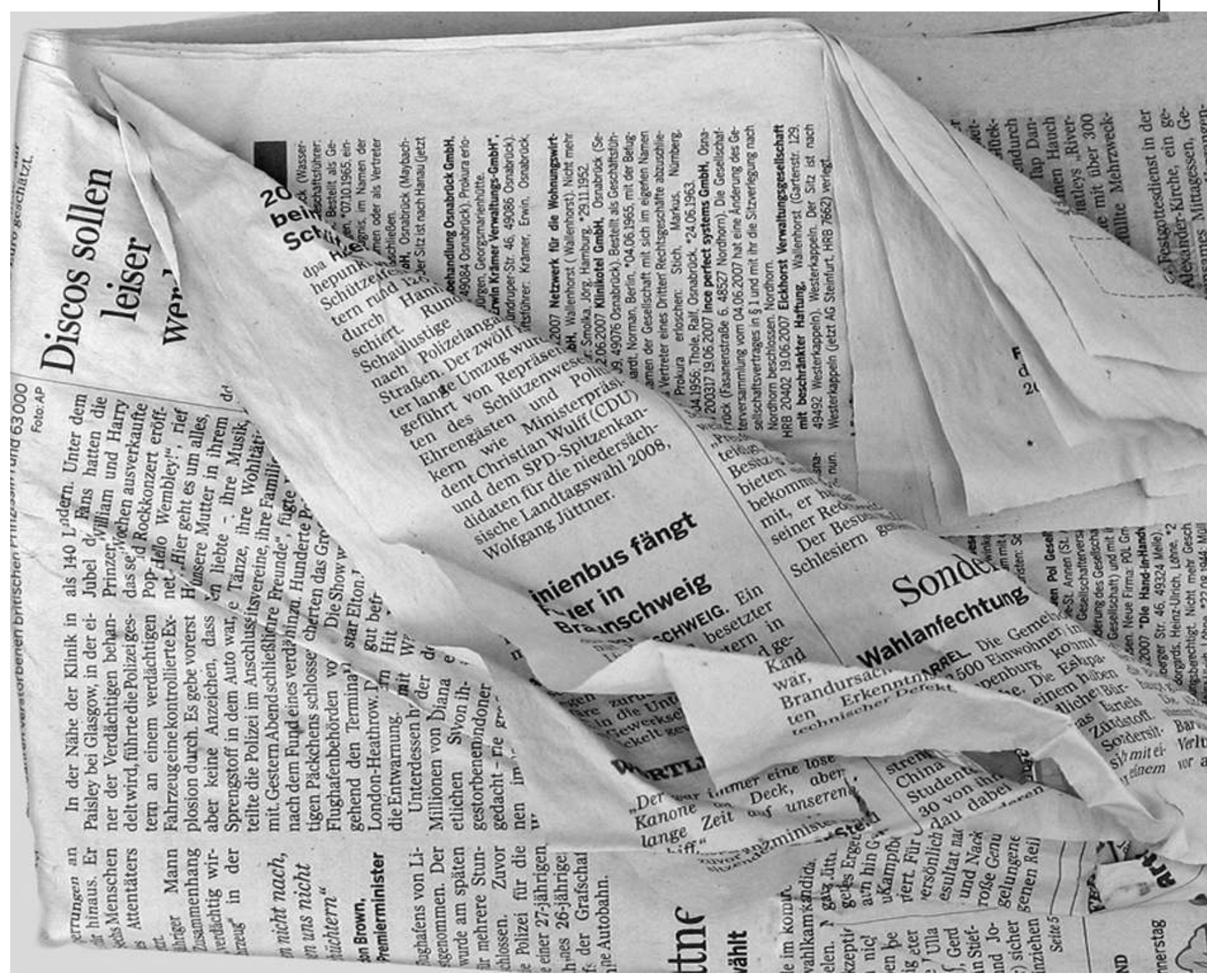

RESUMEN: Este documento hace parte del trabajo de grado "Contra el género y el periodismo mensaje», presentado por los autores como requisito parcial para obtener su título como comunicadores sociales-periodistas de la Universidad del Valle. El trabajo hace una revisión crítica de la Teoría de los géneros periodísticos, en tanto «teoría de la producción periodística». Los autores examinan si dicha teoría, que en los textos de autores como Gonzalo Martín Vivaldi, Luis Martínez Albertos y Mariano Cebrián es

presentada como de carácter científico, cumple o no con los requisitos formales y conceptuales exigidos por la Epistemología para reconocerle a una construcción teórica tal estatus.

De todos los requisitos que como teoría científica debería cumplir la Teoría de los géneros según la Epistemología, Cerón y Perlaza se concentran en dos: 1. La postulación del mensaje periodístico como un pertinente objeto de estudio. 2 . La racionalidad y congruencia de los mecanismos de clasificación de los mensajes periodísticos establecidos por dicha teoría. En este texto los autores se concentran en el primer aspecto.

PALABRAS CLAVE: Teoría de los géneros periodísticos, Periodismo y epistemología, Enseñanza del periodismo. 


\section{El Periodismo}

sin palabras

Germán Perlaza Rúa (ianghera@gmail.com) e Isabel Cristina Cerón (ceron.ceron@gmail.com) Comunicadores Sociales.



RESUMEN: Con este texto se quiere problematizar el género reportaje y proponer una refutación de la

llamada «Teoría de los géneros periodísticos». PALABRAS CLAVE: Reportaje, Géneros periodísticos, Historia del periodismo, Epistemología del discurso

informativo.

ste texto presenta cuatro propuestas fundamentales para amarrar la refutación de la llamada «Teoría de los géneros periodísticos».

1. El problema del Periodismo (el de su mala calidad, el de su vaguedad teórica) es, hasta ahora, y en primer lugar, un problema de índole epistemológica/filosófica. No lingüística, ni ética, ni de rutinas profesionales como se suele asumir, o solo secundariamente de una de estas formas.

2. El Periodismo todavía no define su objeto de estudio/conocimiento, ni sus métodos específicos de trabajo. Todavía no conoce su habilidad específica como ciencia, tecnología o sociotecnología. Es un ejercicio a la deriva, que ha estado sacrificando la oportunidad de constituirse como campo nuevo y consistente, y sobrevive apegado al legado de otras disciplinas, principalmente Literatura, Sociología y Lingüística, con las que a menudo se confunde. El Periodismo no es ninguna de estas tres cosas, y se parece a ellas solo de manera superficial.

3. El objeto de estudio del Periodismo no puede seguir siendo el mensaje periodístico. Ni la enseñanza y la práctica del Periodismo pueden seguir fomentando el énfasis actual en la habilidad para escribir. Hay que mover a la escritura de su lugar central.

4. La Teoría de los Géneros Periodísticos es falsa, vaga e inútil desde el punto de vista epistemológico. Hay que desecharla como herramienta de conocimiento. $\mathrm{Ni}$ el dispositivo género en sí, ni los particulares información, crónica y reportaje, son de alguna utilidad para comprender el trabajo periodístico. Todo lo contrario. La llamada «teoría» ha ayudado a mantener vivo el igualmente falso e inútil parecido entre Periodismo y Literatura.

La asunción positiva de estas propuestas implicaría cambios directos en dos ámbitos. El inmediato: que implicaría sacar a la Teoría de géneros de la Escuela de Periodismo y replantear los componentes de la enseñanza, el estudio y la investigación en el campo, contrarrestando la centralidad actual de la escritura. El investigativo-a largo plazo: que exige a los estudiantes, investigadores y escuelas proponer un nuevo objeto de conocimiento para el Periodismo, que los invita a reconstruir el campo desde cero.

Los fragmentos que escogimos para esta publicación no alcanzan para cubrir la totalidad de estas propuestas. Contienen, apenas, el mínimo necesario para disparar la discusión. Todos fueron tomados de la primera parte del trabajo, por lo que se dedican principalmente a cuestionar la centralidad del texto y el mensaje, y la legitimidad del parecido entre Periodismo y Literatura. Un desarrollo más detallado y ordenado de las mismas y otras ideas 
se encuentra en el texto completo de la tesis de grado. Contacto: ianghera@gmail.com, ceron.ceron@gmail.com.

\section{[...]}

Escribir: no más que una parte del proceso

El Periodismo es más que la redacción de un texto. Periodistas y teóricos están de acuerdo que el hacer periodístico comienza mucho antes que la etapa de redacción.

Comienza, quizá, en la acción de decidir qué hechos son noticia y es seguido por un amplio conjunto de acciones interdependientes, inseparables e incluso simultáneas: rastreo de hechos, selección, jerarquización, reportería y, finalmente, redacción.

Un periodista empieza su día de trabajo consultando las fuentes que le permiten enterarse de los acontecimientos o noticias del día.

Luego atiende a determinado número de reuniones (normalmente una o dos, de sección y generales de redacción) en las que se distribuyen los hechos a cubrir y se traza el perfil de reportería y tipo de información requeridos para la elaboración de cada artículo.

El periodista elige entonces una serie de fuentes de donde obtendrá información, y define y ejecuta las entrevistas, inspecciones o visitas a que haya lugar. Con los insumos a mano vuelve a organizar y seleccionar. Escribe, reescribe, edita. Rebusca nueva información. Finalmente, si cabe, realiza la edición final sobre el diagrama de impresión.

¿Redactar bien? Sí, se requiere esta habilidad. Pero nótese la cantidad de procedimientos previos a la escritura. Y no sólo son muchos, también son claves. Los buenos editores suelen gritar en las salas de redacción que la garantía de un buen artículo está en la cantidad y calidad de información que se recolectó en la investigación. Un periodista puede medir a su editor según la noticia que selecciona o aprueba para cubrimiento, y el lugar que le asigna en la publicación.

En resumen: los periodistas de diarismo suelen invertir tanto o menos tiempo en la etapa de redacción, que el que invierten en cada una de las demás acciones de su jornada (rastreo de hechos, selección, jerarquización, reportería, edición); se puede hablar de noticias muy buenas, por fuera de si están o no bien escritas; y hasta se puede decir que un hecho es noticia mucho antes de que se lo redacte. El Periodismo empieza a ocurrir, pues, mucho antes de que se escriba la primera palabra. Y acaba mucho después de que se ha escrito la última.

Volviendo al comienzo, periodistas y teóricos aparentemente coinciden en esto. Cabría esperar, entonces, que los desarrollos teóricos de la Escuela de Periodismo aspiren a explicar/regular la producción periodística incluyendo la totalidad de estos fenómenos envueltos en ella. Que estudiantes, investigadores, teóricos y Escuelas estén en capacidad de estudiar y explicar no sólo cómo escribir textos periodísticos, sino como seleccionar y descomponer un hecho social, jerarquizarlo frente a otros para ser publicado, definir su relevancia, el método de investigación que le corresponde, el tipo de preguntas que quiere y puede plantearle a ese hecho, los métodos adecuados para resolverlas (cubrimiento/reportería), el resultado que se espera de tal investigación (¿explicación del hecho social? ¿su descripción? ¿mero relato? ¿denuncia?) y, solo finalmente, los usos del lenguaje apropiados para que ese resultado se publique satisfactoriamente -dejando las consideraciones particulares de estilo y extensión a cada empresa particular. Esto es lo que cabría esperar.

Pero cuando se revisa el pensum de las Escuelas y más concretamente cuando se revisa la Teoría de los Géneros Periodísticos (en adelante TGP), lo que se encuentra es que no responden ninguna de estas preguntas. Se ocupan, a duras penas, de ciertos aspectos del estudio del mensaje y la escritura. 


\section{Generalidades de la TGP}

La Teoría de los géneros periodísticos es un planteamiento surgido a finales de la década de 1950 en Europa (concretamente en Francia y España), de manos de un grupo heterogéneo de intelectuales (entre sociólogos, filólogos, críticos literarios, periodistas), cuya cabeza más visible, si hubiese que señalar una, sería José Luis Martínez Albertos ${ }^{1}$. La importancia del planteamiento radica, básicamente, en que constituye hoy todavía el componente teórico principal del currículo académico universitario relativo a la enseñanza del área de Prensa, en las Escuelas de Periodismo o Información, tanto en Latinoamérica como en España. Esto es: goza de excelente salud y credibilidad entre las instituciones y los agentes del campo, es tenida por guía útil para la producción de Periodismo en los medios de comunicación, y de ella se deriva buena parte de la bibliografía de la que se alimenta la Escuela de Periodismo.

Así hablan sus defensores:

- «Cuanto más énfasis se ponga en las enseñanza de los géneros periodísticos en las Facultades de Periodismo y en los departamentos, tanto más el periodismo que se aprende en las universidades será un aprendizaje y una reflexión sobre el periodismo que se hace en los diarios y en las emisoras de radio y de televisión. La teoría y la práctica se encuentran en el estudio de los géneros periodísticos [...]. Con los géneros aprenden actitudes y las actitudes generan hábitos profesionales. Por esos hábitos se conoce quién es el verdadero profesional y quién no lo es. Puede decirse con muchas probabilidades de acierto que el nivel que alcanza la enseñanza de la teoría de los géneros es un buen indicador del nivel científico que haya alcanzado una Facultad». (Santamaría, 1994, p. 43). La llamada Teoría de los géneros periodísticos es un planteamiento de tipo normativo, en el que se establece un conjunto de modelos estilísticos (regularmente tres: información, reportaje y crónica), a los que se supone debe ajustarse la producción de mensajes periodísticos.

Dicho de otro modo, lo que la teoría propone es una división o clasificación («El Periodismo puede ser información, reportaje $o$ crónica») y un criterio de división (los textos calan en una u otra categoría según un supuesto grado de objetividad, interpretación y estilo literario).
Género (clase)

Características : Objetividad, Interpretación, Estilo literario (criterios de división) Información Narración objetiva de los hechos. Mínima interpretación o explicación. Escritura seca (sin adornos).

Reportaje Relato objetivo de los hechos. A diferencia del género información, se espera un primer nivel de interpretación o explicación de los hechos. La mayoría de los tratadistas justifican que en este género ya se escriba con cierto aire literario.

Crónica Relato subjetivo de los hechos. Interpretación y explicación de los mismos también impregnada de la subjetividad del periodista. Escritura con aires, si cabe, más literarios 16.

\section{El mensaje y el texto como objeto de estudio de la TGP}

Explícitamente, la TGP declara que su objeto de estudio es el mensaje/texto:

- «Los géneros periodísticos deben ser para nosotros principios de conocimiento del mensaje informativo, en su dimensión de texto literario, teniendo en cuenta que este mensaje es de alguna manera la expresión de las posibilidades humanas para lograr un cierto grado de comunicación de hechos y de ideas mediante un no desdeñable nivel de creación estética en el uso de la palabra.» (Martínez Albertos, 1992, p.267).

- «Es evidente, por tanto, que a través de los estudios de investigación acerca de los mensajes, su presentación y su contenido, haya una cierta teoría sistemática que permita descubrir y agrupar los textos periodísticos por razón de su género peculiar»(refiriéndose a la Teoría de los géneros periodísticos). (Martínez Albertos, 1992, p.264).

- «La investigación analítica de los géneros lleva a descubrir las reglas y estructuras que los definen, delimitan y diferencian unos de otros. Tal descubrimiento hay que efectuarlo a partir de textos, de realizaciones concretas para ver los elementos comunes, así como las variantes según los usos personales, pero sin perder la estructura global. La teoría de los 
mismos llegará precisamente tras los análisis de las producciones particulares. Analizar los géneros es adentrarse en los mensajes por vía formal para su mejor comprensión. La indagación de los elementos afines a muchas producciones permite una sistematización de las mismas y, por tanto, una mejor comprensión. (Cebrián, 1992, p.16). De forma coherente con su énfasis en el estudio del objeto-mensaje y de la fase de redacción, la Teoría de géneros explica que, para ella, el Periodismo consiste en una operación lingüística:

Martínez Albertos, citando a Lorenzo Gomis:

- «Convertir un hecho en noticia es básicamente una operación lingüística [...] El lenguaje es el modo de captación de la realidad que permite darle forma, aislar dentro de ella unos hechos a los que, por un procedimiento de redacción, se convierte en noticia.» (Martínez Albertos, 1992, p.45).

Idea que se ve reforzada por la descripción de los géneros, a su vez, también como modalidades de creación lingüística o literaria.

- «Géneros periodísticos son, en efecto, las diferentes modalidades de creación lingüística destinadas a ser canalizadas a través de cualquier medio de difusión colectiva y con el ánimo de atender a los dos grandes objetivos de la información de actualidad: el relato de acontecimientos y el juicio valorativo que provocan tales acontecimientos». (Martínez Albertos, 1992, p.213).

- «... Diríamos que géneros periodísticos son aquellas modalidades de la creación literaria concebidas como vehículos aptos para realizar una estricta información de actualidad (o Periodismo)»**. (Martínez Albertos, 1992, p.264).

Venimos de relativizar la importancia del mensaje y la fase de redacción en el trabajo periodístico. Aquí vemos pues, cómo la TGP se equivoca en centrar su objeto de estudio en «el mensaje», y en construir una concepción del hacer periodístico como mera «operación lingüística». ¿Dónde queda el resto del Periodismo?

\section{$[\ldots]$}

Impertinencia del mensaje

Pensemos en la labor del historiador literario o crítico literario. El mensaje/texto es un objeto de estudio pertinente para su labor porque la Historia y Crítica literarias consisten, precisamente, en estudiar textos. Sea para describirlos, clasificarlos o evaluarlos, el trozo de realidad que les interesa es el de los textos.

En el caso específico de la Teoría de géneros literarios, el mensaje/texto es una unidad de estudio pertinente porque el crítico literario encuentra dentro del texto impreso todos los elementos de juicio que necesita para realizar su trabajo, por ejemplo, decidir si la obra es una novela o un poema. La novela es novela, o el poema es poema, sin influencia del número de borradores que los precedieron, el tiempo que tardó el autor en escribirlos, o si sus personajes son imaginarios o inspirados en caracteres de carne y hueso. En otras palabras: no hay nada por fuera del objeto-texto que pueda influir en la decisión sobre el género de una obra. El objeto comienza y termina, entre las páginas primera y última del libro.

Ahora bien: ¿podrá ser también el texto (mensaje) una unidad válida para el estudio del trabajo periodístico?

No. Nos oponemos firmemente a esta idea. Por una razón fundamental.

\section{HACER PERIODISMO NO ES ANALIZAR MENSAJES PERIODÍSTICOS}

De analizar mensajes periodísticos se ocupan la hermenéutica, la lingüística y los estudios de prensa comparada, entre otros. El mensaje/texto es un objeto de estudio válido para estas disciplinas de carácter nítidamente hermenéutico/ 
lingüístico/filológico pues su saber, como el del historiador o el crítico literario, consiste precisamente en clasificar, describir, valorar o diseccionar textos.

Textos son el objeto que estas disciplinas estudian.

Pero no todas las disciplinas estudian textos. No podemos decir, por ejemplo, de la Biología, que su función sea estudiar textos de Biología. Su objeto de estudio no son los libros de Biología, sino los seres vivos.

Los estudiantes leen textos de Biología para aprender Biología. Pero cuando acaban de leerlos, no se sientan a escribir una Tipología de los textos de Biología, sino que van a encontrarse con los seres vivos. Éstos últimos son su objeto de estudio.

Así mismo, la Biología produce teorías sobre los seres vivos, no sobre los textos de Biología. Esta sería, quizá, la tarea de un historiador de la Biología.

$Y$ aunque los resultados de la investigación biológica se pongan por escrito y se distribuyan por la vía de los mensajes impresos, nadie confunde por ello su objeto de estudio (los seres vivos) con dichos textos.

Es importante, pues, aprender a diferenciar el texto como herramienta de estudio (común a todas las profesiones) y el texto como vía para exponer los resultados de la investigación en la profesión (también común a todas las profesiones), del texto como objeto de estudio de la profesión. Este último, insistimos, es común sólo a las profesiones de carácter filológico, hermenéutico o lingüístico.

En el caso del Periodismo:

Se pueden leer textos para aprender a hacer Periodismo (texto como herramienta de estudio). También se consignan los resultados del trabajo periodístico en textos, llamados mensajes periodísticos (texto como vía para exponer resultados de investigación).

Pero si hubiésemos de forzar una definición del objeto que estudia, analiza, disecciona, ordena o clasifica el Periodismo, (decimos forzar porque dicha definición todavía no existe), entonces quizá cabría hablar de hechos. Lo que el Periodismo (el periodista) estudia son hechos. No textos.

Podría alegarse que el periodista (también el sociólogo, el antropólogo, el historiador) se ve constantemente obligado a analizar mensajes o textos en sus investigaciones, como cuando examina, por ejemplo, un documento público. Pero aún en estos casos, hay que aceptar y aprender a distinguir que el periodista (el sociólogo, el antropólogo, el historiador) no accede a dichos textos en calidad de textos, sino en calidad de hechos, o registros de un hecho. El texto como insumo en la investigación le sirve para sacar conclusiones sobre otros hechos, no para sacar conclusiones sobre la naturaleza lingüística o literaria de ellos en cuanto textos. Dicho lo anterior, y teniendo siempre en mente la diferencia entre el objeto hecho y el objeto mensaje, afirmamos que una teoría periodística no podría dedicarse al objeto de estudio «mensaje periodístico», sino sólo, quizá, al objeto (aún incipiente) «hecho periodístico». $\mathrm{Si}$ el Periodismo estudia hechos en vez de mensajes, una teoría como la de los géneros periodísticos, que se dedica al estudio del «mensaje periodístico», no es ni puede considerarse una teoría periodística: ni desde, ni para el Periodismo. Sólo puede ser, acaso, una teoría desde y para la Filología, la Crítica literaria/periodística, la Lingüística o la Morfología.

Vale la pena releer los tratados de géneros bajo esta perspectiva y comprobar que, si bien es posible que la teoría sirva para algo, ese algo no tiene nada que ver con hacer Periodismo. La Teoría de géneros se parece mucho más a un listado de señas estilísticas encontrables en los textos acabados (útil para las profesiones de tipo hermenéutico mencionadas), que a una guía viva sobre cómo rastrear hechos y acontecimientos, medir su noticiabilidad, clasificarlos, jerarquizarlos, determinar el tipo de reportería adecuado para cubrirlos y su posterior tratamiento, etc., entre tantas tareas que constituyen el verdadero trabajo del periodista y sobre las cuales la Teoría de los géneros periodísticos no dice nada.

Haber limitado el estudio del Periodismo al «mensaje»y/o el «texto periodístico» es el primer error que le señalamos a Teoría de géneros. Creer y hacer creer que pregunta «Cómo hacer Periodismo», cuando en realidad sólo pregunta «Cómo se redactan los mensajes en estilo periodístico».

$[\ldots$

Géneros: falsa analogía con la literatura

La adopción del género como eje/noción central de la teoría de los géneros periodísticos, se justifica en los manuales como resultado de un « cierto mimetismo científico» con la Literatura:

- «Centrando nuestro objetivo en el periodismo impreso, digamos para empezar que esta preocupación ha surgido por razón de un cierto mimetismo científico. Por similitud a 
los géneros literarios, tópicos en toda la Preceptiva literaria, los estudiosos del periodismo han señalado igualmente la existencia de determinados géneros pe riodísticos. No se trata, sin embargo, de una distinción puramente bizantina o erudita. Su utilidad se revela particularmente interesante en el campo de la enseñanza y de la preparación de los futuros profesionales de la información de actualidad, en primer lugar». (Martínez Albertos, 1992, p.263).

- «La teoría de los géneros periodísticos es, evidentemente, una construcción teórica que surge por extrapolación de la teoría clásica de los géneros literarios. Desde este punto de vista, los teóricos de los géneros periodísticos reconocen gustosamente el vasallaje debido a los estudios de Poética sobre los estilos y los géneros literarios y se consideran a sí mismos como sujetos obligados a pagar un legítimo feudo a los grandes señores naturales de este campo científico. A partir de este reconocimiento de dependencia doctrinal, los principios inspiradores del mecanismo productor de la teoría de los géneros y estilos literarios es perfectamente aplicable al campo de los géneros periodísticos». (Santamaría, 1991, p.107)

Tal analogía es un error, decimos, porque parte de dos premisas falsas:

Premisa falsa \#1: «Los géneros explican/dirigen la producción literaria» Si los tratadistas creían -como dicen- que existe una similitud entre la labor del periodista y la del escritor, entonces lo correcto habría sido adaptar al Periodismo una teoría de la Literatura, esto es, una teoría sobre el proceso vivo de creación de textos y relatos.

Pero una teoría ${ }^{2}$ de este tipo no existía entonces, ni existe todavía. Las artes (incluyentes del arte de escribir) gozan de un estatus de excepción respecto a la ciencia y las explicaciones por la vía racional que casi es parte constitutiva de su propia definición como arte: el arte es, por esencia, indefinible, inefable, irreglamentable, inescrutable. Desde este punto de vista, paradigmático del campo artístico hasta nuestros días, la creación literaria no podría reducirse jamás a un conjunto de reglas teorícas o manualística.

No existe, repetimos, ninguna teoría literaria científica (desde y para los escritores).

¿Qué hicieron entonces los tratadistas?

Lo que hicieron fue adaptar al Periodismo una teoría que, si bien se relacionaba de algún modo con la Literatura, no era ni de la Literatura, ni sobre cómo escribir obras literarias -sobre el proceso vivo de creación. Los géneros literarios son una teoría de la Historia/Crítica literaria, sobre cómo describir/clasificar obras literarias acabadas.

En términos lógicos, los tratadistas plantearon la analogía:

Si $A=B$

teoría sobre $\mathrm{A}$ = teoría sobre $\mathrm{B}$.

(Donde $\mathrm{A}=$ Literatura, $\mathrm{B}=$ Periodismo)

Pero no existe una teoría sobre A.

La solución de los tratadistas fue tomar por teoría sobre A, otra teoría (C) que cumplía una función aparentemente idéntica.

Si $\mathrm{A}=\mathrm{B}$ : teoría sobre $\mathrm{C}(?)=$ teoría sobre $\mathrm{B}$. (Donde $\mathrm{C}=$ Crítica/Historia literaria) 
Preguntamos: ¿Será la misma cosa hacer Literatura que hacer Historia o Crítica de la Literatura? ¿Podrán servirse de la misma teoría, sólo porque compartan el trozo de realidad Literatura?

No, en primer lugar, porque el hacer del historiador/crítico es distinto al del escritor. Una teoría que es útil para dirigir el trabajo de los primeros, no puede dirigir igualmente el trabajo de los segundos. Cuando los tratadistas trazan esta segunda analogía (incorrecta), están asumiendo que Literatura es igual a Crítica/ Historia literaria $(A=C)^{3}$.

No, en segundo lugar, porque los géneros, aunque se los traiga a la fuerza y se los obligue a dirigir la Literatura, se quedan inevitablemente cortos frente al problema de la producción. Por una cuestión de carácter, de vocación, el género tiende a reducir lo que estudia a una cantidad limitada de categorías formales (la teoría clásica reconoce tres: épica, lírica y poesía). Ésta es la función que fue llamado a cumplir en la Historia y la Crítica literaria. Pero una cosa es el provecho que estas categorías brindan a estas disciplinas, y otra muy distinta que, viendo esta utilidad (discreta, limitada), se decida convertirlas en normas y moldes para las sucesivas producciones literarias.

Benedetto Croce, filósofo italiano, alertaba ya sobre este problema en 1938, en la segunda lección de su Breviario de Estética, con el cual apuntaba a deshacer esta confusión en el seno mismo de los estudios literarios:

Cerraré la enumeración de los prejuicios sobre el arte, reseñando los de mayor uso, porque se mezclan en la vida cotidiana de la crítica y de la historiografía artística; con el prejuicio, en primer lugar, de la posibilidad de distinguir varias 0 muchas formas particulares de arte, determinada cada una en su concepto particular, en sus límites, y provista de leyes propias. Esta errónea doctrina toma cuerpo en dos series sistemáticas, una de las cuales es conocida como teoría de los géneros literarios o artísticos [...] Muchos estéticos componen hoy mismo tratados sobre la estética de lo trágico, o de lo cómico, o de la lírica, o del humorismo, y estéticas de la pintura, de la música, de la poesía [...] razonando sus impresiones y diciendo que observan o que violan las leyes del drama, o de la novela, o de la pintura, o del bajorrelieve [...].
La historia literaria está llena de casos en los que el artista genial ofende con su obra a un género establecido, suscitando la reprobación de los críticos. Reprobación que no logra, por lo demás, sofocar la admiración o la popularidad que ha despertado la obra, hasta que, al fin, no pudiendo descalificar al autor ni queriendo tampoco estar a malas con los críticos de los géneros, se acaba generalmente con una componenda, ampliando el género en cuestión o haciendo brotar junto a él otro género nuevo a guisa de hijo bastardo [...]. Como cada obra de arte expresa un estado de alma, y el estado de alma es individual y siempre nuevo, la intuición supone intuiciones infinitas que no nos es posible encerrar en un casillero de géneros, a menos de que esté compuesto de infinitas casillas de intuiciones y no de géneros. Como, por otra parte [...] la poesía y la pintura no valen por los sonidos que emiten en el aire o por los colores que refractan de la luz, sino por lo que saben decir al espíritu en cuanto se adentran en él, es inútil dirigirse a los medios abstractos de la expresión para construir otra serie de géneros y de clases [...] . (Croce, 1943. P. 56)

El argumento principal de Croce contra los géneros es el de la unicidad de la expresión/ intuición artística. Siendo ésta siempre única, requerirá también de formas únicas para expresarse. Es, pues, irreductible a un catálogo limitado de preceptos formales - géneros. Desde nuestro punto de vista, sin embargo, agregaríamos que tal unicidad no es propia sólo de la producción artística, sino de la producción de contenidos (ideas) en general. El Periodismo, la Historia, la Antropología, cuando cuentan sus hallazgos, procuran el esquema narrativo (forma) que sirva mejor a los contenidos y el sentido de su producción. Su fin no es el de encajar en un molde o esquema formal. Todo lo contrario: cada que sea preciso, el escritor/periodista/historiador inventará una forma completamente nueva si esto conviene al desarrollo de su relato.

Cuando Croce esgrime contra los géneros la unicidad de la intuición artística, creemos que, teniendo razón, podría ir más lejos. Los géneros hacen estorbo, en general, a la expresión de 
cualquier idea o razonamiento (artístico, científico, o de cualquier índole) al pretender que preexistan las formas a los contenidos. Y lo que es peor: que preexistan en un catálogo tan extremadamente limitado de ellas. A este catálogo limitado de formas, no sólo oponemos, como Croce, las infinitas intuiciones artísticas, sino en general, los infinitos contenidos producibles por todas las disciplinas artísticas y no artísticas.

El estudio de las formas, y por ende su clasificación y reducción a unos principios básicos, es de interés sólo para los lingüistas morfólogos o los historiadores de la literatura (estudiosos del texto en cuanto texto). Pero no tiene sentido desde el punto de vista de la producción ni literaria ni periodística. Otra forma de expresar este mismo problema es sugerir que los géneros pueden ser útiles como preceptiva (enseñanza) en la Historia del arte, pero no como norma ni como prospectiva de la creación artística (molde en el que deberán encajar las producciones futuras).

- «Aunque ni el puro artista, ni el puro crítico, ni el puro filósofo tropiecen con generalia, con géneros y clases, éstas prestan su utilidad en otros respectos. En esta utilidad estriba el lado verdadero, que no quiero dejar de mencionar, de tan erróneas teorías. Conviene tejer esta red de generalia, no para la producción que es espontánea del arte, ni para el juicio que es filosófico, sino para recoger y circunscribir de algún modo, auxiliando la atención y la memoria, las infinitas intuiciones singulares que sirven para enumerar parcialmente las innumerables obras de arte.

(...) Estos géneros y clases facilitan el conocimiento y la educación artísticos, dando al conocimiento como un índice de las obras de arte más importantes y facilitando a la educación una suma de las advertencias más urgentes que sugiere la práctica del arte. Todo estriba en que no confundamos los índices con la realidad, y los acaecimientos e imperativos hipotéticos con los imperativos categóricos, consecuencia a la que podemos ir con facilidad, pero a la que se puede y se debe resistir». (Croce, 1943. p. 58)

Regresando al tema que nos ocupa en este punto, no se puede confundir a la Teoría de géneros literarios con una teoría sobre la producción literaria. Es, apenas, una teoría para la Crítica o la Historia literaria.

Y no siendo una teoría válida para la producción literaria, no hay cómo decir que sus mecanismos puedan servir también para explicar la producción periodística.

El objetivo de los tratadistas era justificar el uso de la Teoría de géneros, asimilando Literatura y Periodismo.

El error de tal aproximación fue confundir a los géneros con una teoría de la Literatura.

Error que se comete contra la Literatura en primer lugar; y que termina instalado en el Periodismo.

\section{ii. Premisa falsa \#2: «Literatura = Periodismo»}

El segundo error en el razonamiento del «mimetismo científico», es haber creído que entre Literatura y Periodismo existía un parecido relevante.

El Periodismo, afirmamos, sí se parece a la Literatura, pero la semejanza es teóricamente desechable. Por dos razones («por un lado»/ «por otro lado»).

Por un lado, desde la Epistemología de la Ciencia, es teóricamente irrelevante parecerse a la Literatura porque, ya lo dijimos, la Literatura no admite explicación teórica científica alguna. $\mathrm{El}$ arte, en general, rehúsa cualquier acercamiento de tipo científico (objetivo). Y así: ¿Qué consecuencias teóricas podría tener una eventual semejanza con la Literatura? Ninguna. No hay posibilidad de parecerse teóricamente a ella.

Más bien, una semejanza en este sentido conduciría a considerar al Periodismo también como un arte, es decir, como una disciplina inescrutable e irreductible, razonamiento que anularía inmediatamente la posibilidad de fundar cualquier teoría científica a partir de ella, entre ellas, la de los géneros periodísticos. Los tratadistas tenían pues dos opciones:

a) Afincarse en el parecido con la Literatura, incluir al Periodismo entre las artes y olvidarse de una vez de su deseo de construir una teoría científica sobre el Periodismo.

b) Desechar el parecido con la Literatura, desechar la idea del Periodismo como arte, y emprender una teorización científica sobre el Periodismo. Pero tal teorización, en este caso, no podría estar fundada en ninguna relación con la Literatura.

Como se ve, ambas opciones excluyen cualquier posibilidad de una Teoría de los géneros periodísticos.

Es una sorpresa, pues, el camino que escogieron los tratadistas: fundar una teoría «científica»a 
partir del parecido con una disciplina artística. Este es el sinsentido que da lugar a la Teoría de los géneros periodísticos.

Que no quedó sin consecuencias. Mencionamos dos:

Ambigüedad Arte/Ciencia

En primer lugar, la teoría patrocina un tipo de profesional híbrido: que con la anarquía teóricometodológica del artista pretende resolver problemas que corresponden a las Ciencias Sociales; que unas veces se ciñe al rigor de la investigación y la duda, y otras se arriesga a la subjetividad y aún a la ficción para brindar explicaciones sobre lo social; y que todo esto lo celebra por parejo, cómodamente, como artista y como científico social.

¿Acaso no conoce el Periodismo la diferencia entre las llamadas verdades del arte y las de la Ciencia? ¿Con qué responsabilidad se plantea la profesión esta disyuntiva?

¿Y qué tan enterados están los lectores sobre esta cuestión? ¿Con qué franqueza se le dice al lector del periódico y al espectador del telediario que lo que lee o ve es una obra de arte? ¿Conoce y acepta el lector las licencias que el periodista, como artista, puede tomarse en el tratamiento y presentación de los contenidos?

\section{Cobardía teórica}

En segundo lugar, y desde el punto de vista epistemológico esto es lo más grave, la ambigüedad arte/ciencia crea un cuerpo teórico cobarde y flojísimo.

Se formulan teorías llamadas científicas, como la de los géneros, pero a la primera dificultad, inconsistencia o contradicción, se disculpa el bache como manifestación de la mitad artística. Si no se entiende, si no se sabe qué es, es puesto de inmediato en estado de excepción.

No se trata de que la explicación científica deba predominar sobre o anular al arte, sino de señalar el absurdo que constituye lanzarse a hacer teorías "científicas» con malla de seguridad. En el juego de la Ciencia, si la hipótesis se cae, se cae del todo. Sin excepción.

La inefabilidad, la irreductibilidad o la inescrutabilidad de ciertas hazañas, puede que tengan sentido y se celebren desde el punto de vista artístico, pero desde el punto de vista científico son apriorismos que hay que eliminar. 'Lo inexplicable', en otras palabras, podrá ser el reto del científico, nunca su disculpa.

De modo que es irrelevante (y prácticamente imposible) parecerse teóricamente -desde una perspectiva científica- a un arte.
Por otro lado, decimos que la semejanza entre Periodismo y Literatura es teóricamente irrelevante porque, aunque existen caracteres comunes a ambas disciplinas, dichos caracteres son intrascendentes y superficiales.

\section{Superficiales en su enunciación}

El primer error de los tratadistas a este respecto es no haber justificado de forma explícita, clara y suficiente en qué consistía la supuesta similitud entre Periodismo y Literatura. ¿En qué se parecen los objetos, objetivos, metodologías y resultados de ambas disciplinas, que hace posible y provechoso trazar una analogía teórica entre las dos?

La similitud, en todos los casos, se da por evidente/obvia, y se procede directamente a la adaptación del mecanismo (Teoría de géneros) ${ }^{5}$. El problema es que cuando se trata de analogías teóricas entre disciplinas ( $\mathrm{y}$ no de comparaciones o metáforas en un poema), el investigador que omite justificar un préstamo teórico no comete un olvido inocuo, sino que se expone: a "captar solamente las semejanzas exteriores» de lo que estudia, a caer en la «evidencia» que es «enemiga del rigor» $y$, sobre todo, a acabar forzando/sometiendo su objeto a una explicación teórica falsa e inadecuada. Las frases entre comillas son de P. Bourdieu, y el problema aludido es lo que se conoce como una «formalización sin control epistemológico»:

«Confundiendo entre la simple semejanza y la analogía, relación entre relaciones que debe ser conquistada contra las apariencias y construida por un verdadero trabajo de abstracción y por una comparación conscientemente realizada, los modelos miméticos, que no captan más que las semejanzas exteriores se oponen a los modelos analógicos que buscan la comprensión de los principios ocultos de las realidades que interpretan. «Razonar por analogía, dice la Academia, es formar un razonamiento fundado en las semejanzas o relaciones de una cosa con otra» o más bien, corrige Cournot, «fundado en las relaciones o semejanzas en tanto éstas muestren las relaciones»»». (Bourdieu, 1978, p.78)

«Es éste el procedimiento que le confiere su fecundidad, es decir su poder de generalización, a las comparaciones entre sociedades diferentes o entre subsistemas de una 
misma sociedad, por oposición a las simples comparaciones suscitadas por la semejanza de los contenidos. En la medida en que estas «metáforas científicas» conduzcan a los principios de las homologías estructurales que pudieran encontrarse sumergidas en las diferencias fenomenales, son, como se ha dicho, «teorías en miniatura» puesto que, al formular los principios generadores y unificadores de un sistema de relaciones, satisfacen completamente las exigencias del rigor en el orden de la demostración, y de la fecundidad en el orden del descubrimiento, que definen una construcción teórica [...]».(Bourdieu, 1978, pp. 80-81).

No se trata, pues, de asemejar por asemejar, sino de asemejar para descubrir un sistema de relaciones fecundo entre ambas disciplinas, válido sólo en la medida que dichas relaciones queden suficientemente expuestas/reveladas, pues sólo así se las puede verdaderamente aprovechar y, cómo no, verificar o refutar. Una analogía teórica superficial, como la que emprendieron los tratadistas con la Teoría de géneros, es una acción epistemológica descontrolada, y en ello ya constituye un error.

Superficiales en su esencia No nos dejan otro camino los tratadistas, pues, sino encontrar y estudiar por nosotros mismos las semejanzas entre Literatura y Periodismo. ¿En qué se parecen? Y, ¿justifica el parecido un préstamo teórico? Adelantando nuestra conclusión, diremos: sí existen semejanzas, pero superficiales. Y en cambio, hay al menos una diferencia fundamental entre ambas disciplinas. Dicho de otro modo: no encontramos cómo justificar una analogía teórica; sí, por el contrario, una razón de peso para impedirla.

¿En qué se parece la Literatura al Periodismo? La idea explícita más fuerte entre los tratadistas de una relación entre ambas es la que describe al Periodismo como un género o subgénero literario (un lugar común tanto en los tratados de géneros periodísticos como fuera de ellos). La pregunta es, ¿qué hay en el Periodismo que nos haga pensar en él como Literatura?

Tras pensarlo largamente, sólo se nos ocurren dos razones. La primera, es que el Periodismo se parece a la Literatura en que, como ella, cuenta o narra, y en que inicialmente el vehículo de tal narración es el lenguaje escrito.

La segunda es que el Periodismo, como la Literatura, quiere contar lo que cuenta bellamente ${ }^{6}$.

Respecto a la necesidad de narrar, y de hacerlo por medio escrito, se trata de una similitud intrascendente.

¿Es acaso la capacidad o necesidad de narrar exclusiva de la Literatura? Narran también la Antropología, la Astronomía, la Biología evolutiva y, por defecto, cualquier otra disciplina de carácter histórico, incluyendo a la Historia. Todas ellas cuentan, porque es el vehículo natural para comunicar sus hallazgos (necesariamente históricos; que tienen un desarrollo en el tiempo). El relato o la necesidad de narrar historias no son más propias de la Literatura, de lo que puede serlo para alguna de estas ciencias. Y pese a ello, ni el Periodismo se asimila teóricamente a la Historia o la Astronomía por razón del relato, ni la Historia o la Astronomía se conciben a sí mismas como ramas o subproductos de la Literatura. Es más, no podemos afirmar que el relato nos asemeje a la Literatura porque la Literatura no es sólo o esencialmente relato: el narrativo es apenas uno de los tres modos que le reconoce la Teoría de géneros literarios, junto al lírico y el dramático ${ }^{7}$. En esta semejanza teórica Periodismo-Literatura a través de los géneros, ¿a dónde van a parar esos otros $2 / 3$ de Literatura a los que el Periodismo no se parece? 
De modo que ni el relato es una propiedad exclusiva de la Literatura (sino que es común a muchas disciplinas), ni la Literatura consiste en sólo relatos (hay dos modos expresivos adicionales -poesía, drama- que no se relacionan con el ejercicio periodístico).

El factor relato es, pues, insuficiente para justificar una analogía teórica con la Literatura. Respecto a la segunda semejanza, la de aspirar el periodista a narrar con la misma eficacia, amenidad e interés de los que es capaz el escritor de Literatura, tampoco podemos decir que sea una característica esencial -ni exclusiva- del Periodismo.

Es cierto que el periodista (también el historiador, el antropólogo, etc.) quiere no sólo narrar, sino, además, ser un buen narrador. Pero también es cierto que puede seguirse hablando de Periodismo (y de Historia y de Antropología) aunque falte calidad literaria. No podemos decir, entonces, que sea un caracter esencial del Periodismo.

Todo lo contrario: el más común es el periodismo seco -sin ínfulas narrativas o estílisticas- propio de los afanes del diarismo. ¿Cuántos artículos de prensa se publican regularmente que apenas cumplen con los requisitos básicos del lenguaje informativo? Y siguen siendo Periodismo'. Tan prescindible es la belleza literaria para el Periodismo, que la misma Teoría de géneros periodísticos se vio obligada a admitir entre sus géneros, un tipo de texto con belleza literaria nula: el llamado género información, al que Martínez Albertos describe como el más «escueto»y «descarnado... desde el punto de vista de la apariencia formal del lenguaje utilizado por el reportero» (Martínez Albertos, 1992, p.288).

De modo que, si bien existen textos de prensa muy bien contados, la habilidad narrativa de tipo literario no es condición, norma o esencia de la producción periodística.

Entonces tenemos que existen al menos dos semejanzas entre Periodismo y Literatura, pero ninguna que pueda llamarse teóricamente relevante.

Y, en cambio, sí podemos decir que entre Periodismo y Literatura existe al menos una diferencia fundamental.

Para que haya Periodismo es necesario, siempre, que se reporteen y se narren hechos reales. No así en Literatura.

«¿Y qué son hechos reales?» - opondrán algunos, aludiendo a la vieja discusión filosófica sobre la (no) objetividad de la percepción humana. «¿Cómo puede hablarse de un Periodismo de hechos reales cuando no es humanamente posible acceder a tal «realidad»?»

A lo que respondemos:

Esta pregunta ha desvelado durante siglos a las

Ciencias naturales y sociales.

Reconocer esta separación ontológica entre lo real y lo humanamente cognoscible fue, precisamente, lo que en el siglo pasado llevó a la Ciencia a replantear y relativizar sus alcances: ya no se habla de verdades absolutas, sino de respuestas más o menos aproximadas (objetivas), según el método científico moderno. Pero no por esto abandonó la Ciencia la búsqueda de la objetividad o el recurso a la racionalidad y se lanzó a inventar explicaciones de tipo metafísico, imaginario o poético sobre los hechos (como la Literatura), porque que es precisamente esta aproximación, este constante apelar a la objetividad, lo que dota de sentido a la investigación científica y la distingue de otras formas de saber, como el sentido común y el arte. La búsqueda de la objetividad no es, pues, menor o menos intensa, hoy en día que hace 150 años; sino sólo distinta.

Respecto al Periodismo, puede que aún no se declare su adhesión completa a las Ciencias Sociales (dice ser, todavía, medio arte), pero lo cierto es que comparte con ellas este carácter objetivo.

No importa cuánto se defienda el estatuto artístico del oficio, en Periodismo no se admiten relatos o explicaciones de índole imaginaria o poética. La objetividad es tan esencial al Periodismo como a las Ciencias sociales.

En Literatura, por el contrario, no es necesario/ esencial que lo narrado haga referencia a hechos reales. Por el contrario, la invención es vista como un valor, y se la celebra como señal de creatividad.

En Periodismo (como en Ciencias sociales), la invención es un antivalor, y se la conoce como mentira (o error, o locura).

Literatura y Periodismo se diferencian, pues, en este punto. Un punto esencial, decimos, porque pudiendo prescindir de la belleza o la amenidad literaria (cualidad superficial), no puede prescindir de la objetividad o aproximación en lo que observa y narra (cualidad esencial).

Y si el Periodismo no puede prescindir de la objetividad, entonces tampoco puede prescindir de teorizar sobre ella ni, como en este caso, utilizar para sí una teoría que no la tenga en cuenta. La Teoría de los géneros periodísticos, sólo reglamenta la práctica periodística en su «dimensión lingüística», descuidando la totalidad 
de las prácticas previas, que son las que pueden garantizar que exista aproximación u objetividad en el tratamiento periodístico. Entonces tenemos que, habiendo entre Periodismo y Literatura sólo semejanzas superficiales, existe, al menos, una diferencia fundamental.

En otras palabras:

No hay semejanzas relevantes que justifiquen una analogía teórica científica entre Literatura y Periodismo.

Sí hay, en cambio, una diferencia esencial que impediría una analogía teórica con la Literatura.

Por todo lo anterior, decimos que la analogía teórica LiteraturaPeriodismo que propone la Teoría de géneros es científicamente falsa e inconveniente para el desarrollo del Periodismo por la vía científica. Haber igualado teóricamente Periodismo y Literatura es otro gran error de la TGP.

Con todo, era mucho más probable que nos pareciéramos teóricamente a la Historia, la Sociología o la Antropología, con las que compartimos -además del interés por lo social y lo humano- tanto la herramienta relato, como la preocupación por dar respuestas científicamente aproximadas.

Hasta hoy, no existe razón alguna epistemológicamente relevante ni suficiente que justifique la adaptación de la Teoría de los géneros literarios al Periodismo.

$[\cdots$

La breve historia (no contada) de los Géneros Periodísticos El descontrol epistemológico que acabamos de criticar, se puede explicar parcialmente examinando el desarrollo histórico del planteamiento.

En contraste con la antigüedad que sugieren los términos crónica, información y reportaje ${ }^{10}$, y la antigüedad misma de la Teoría de los géneros literarios (que vienen de Aristóteles), la Teoría de los géneros periodísticos surgió formalmente apenas en 1959. Y sin embargo, en este breve plazo ha tenido una vida de teoría extremada y sospechosamente agitada: ha sido adaptada para servir a por lo menos tres disciplinas (enfoques) distintas y soportado al menos dos decenas de revisiones.

Primero, Sociología

Según Santamaría (1991), el primer uso registrado del género en relación con el Periodismo es responsabilidad de Jacques Kayser, un catedrático francés asociado a la Unesco que tomó prestada la herramienta de la Crítica Literaria para realizar un estudio de prensa comparada (sociología cuantitativa).

\footnotetext{
- «Conviene, no obstante, hacer aquí una aclaración de carácter histórico, en relación con los estudios e investigaciones sobre la Comunicación Periodística. Uno de los primeros estudiosos de alcance internacional que utilizó el concepto de género periodístico fue Jacques Kayser, en los últimos años de la década de los 50. En 1961 recogió, en una modesta edición en ciclostil, su trabajo El Periódico. Estudios de morfología, de metodología y de prensa comparada', editado en Quito por la CIESPAL (Centro Internacional para la Enseñanza Superior del Periodismo en América Latina). Su método de análisis de los periódicos tuvo en aquellos años una amplia
}

difusión por todo el mundo occidental (Europa y América), como consecuencia de seminarios y cursos organizados por la UNESCO. Jacques Kayser, efectivamente utilizó el concepto de géneros periodísticos como uno de los criterios para la clasificación de los textos de los periódicos, de acuerdo con una técnica de disección valorativa del material impreso que él venia explicando por todo el mundo por lo menos desde unos cinco años antes de la publicación de su trabajo en Quito -es decir, desde 1955, aproximadamente.» (Santamaría, 1991, p.108).

Hasta este momento, el asunto todavía resultaba inofensivo para el ejercicio periodístico. El profesor Kayser, si bien se preocupaba por los contenidos del periódico, lo hacía desde las inquietudes y el punto de vista de la Sociología: lo suyo era un estudio de prensa comparada, no un manual de producción periodística. En otras palabras: aún no se confundía el enfoque descriptivo y clasificador de textos, con un enfoque propicio para explicar la producción de Periodismo. Ni los géneros habían entrado, todavía, a hacer parte de la Escuela de Periodismo.

La aclaración precisa, a mi juicio, es que en el panorama internacional de los estudios sobre Periodismo la teoría clasificatoria de los géneros periodísticos no se hizo inicialmente con una preocupación filológica o literaria, sino descaradamente 
sociológica. El criterio clasificatorio de los géneros periodísticos es uno de los procedimientos descriptivos que utiliza Kayser para proceder a una valoración cuantitativa de los mensajes que aparecen en los diarios». (Santamaría, 1991, p.108109).

Luego, Filología

El siguiente uso de los géneros periodísticos, según Santamaría, se intentó desde el campo de la Filología. La clave en este punto, es que este nuevo uso de la teoría sí ocurre dentro de la Escuela de Periodismo, específicamente en la Universidad de Navarra, una de las primeras en darle el visto bueno a la teoría.

De acuerdo con los datos que he podido reunir, fue la Universidad de Navarra uno de los primeros centros de investigación en el mundo occidental -y puede que, tal vez, sea el primero- donde se empezó a trabajar sistemáticamente con la Teoría de los Géneros Periodísticos a partir de un enfoque filológico». (Santamaría, 1991, p.109).

Finalmente, producción periodística Es en esta misma escuela, la de Navarra, donde ese segundo enfoque filológico acaba misteriosamente transformado en periodístico. $\mathrm{El}$ desliz ocurre en el momento en que se liga el enunciado "géneros periodísticos» a la cátedra que enseña cómo redactar textos periodísticos.

Desde comienzos del curso 1959-60, en el Instituto de Periodismo de la Universidad de Navarra se explicó en el plan de estudios la asignatura Redacción Periodística con el enunciado añadido de «Los géneros periodísticos». El encargado de esta materia en aquellos primeros años fue el profesor Martínez Albertos ${ }^{11 " .}$

(Santamaría, 1991, p.109).

A partir del curso siguiente 1960-1961 apareció en Pamplona una primera edición en ciclostil, de los Guiones de clase de Redacción Periodística (Los géneros periodísticos), texto que tuvo una asombrosa difusión en España y en América, gracias a repetidas reimpresiones que duran, por lo menos, hasta 1974, fecha en que el profesor Martínez Albertos publicó en Barcelona Redacción Periodística: los estilos y los géneros en la prensa escrita». (Santamaría, 1994, p.42).

La justificación de este traspaso, repetimos, no consta en los manuales. Simplemente, como admite Santamaría (1991, p.109), los tratadistas reconocieron un «evidente» vasallaje del
Periodismo frente a la Literatura, y con esto les bastó para considerar los géneros como «perfectamente aplicables» a su estudio. -»La teoría de los géneros periodísticos es, evidentemente, una construcción teórica que surge por extrapolación de la teoría clásica de los géneros literarios. Desde este punto de vista, los teóricos de los géneros periodísticos reconocen gustosamente el vasallaje debido a los estudios de Poética sobre los estilos y los géneros literarios y se consideran a sí mismos como sujetos obligados a pagar un legítimo feudo a los grandes señores naturales de este campo científico. A partir de este reconocimiento de dependencia doctrinal, los principios inspiradores del mecanismo productor de la teoría de los géneros y estilos literarios es perfectamente aplicable al campo de los géneros periodísticos.»

(Santamaría, 1991, p.107).

Desde nuestro punto de vista, tantos cambios en tan poco tiempo sólo tienen una explicación: descontrol epistemológico. Efectivamente, ninguno de estos traspasos ha quedado huella de reflexión epistemológica alguna. No se escudriñan los objetos de estudio, los mecanismos, las distinciones entre las disciplinas. La noción de género, especialmente dócil para este propósito, pasa de una disciplina a la otra con la informalidad de un consejo: esto funcionó aquí, prueba si funciona también allá. Los intelectuales la comparten sin celo, como se comparten una fábula o una parábola.

Esta es la breve historia de los géneros en el Periodismo. Una cadena de préstamos científicamente ilegítimos que, sin embargo, queda certificada cuando se asienta en la Escuela. La validez de la Teoría de los géneros periodísticos descansa, prácticamente, en los brazos de esta institucionalidad. Los géneros se ponen a resguardo en la institucionalidad de la Academia, y la Escuela se apoya en la Teoría de géneros para exhibirse como campo de estudio maduro y «científico». Los géneros periodísticos le prestan a la Escuela de Periodismo una herramienta pedagógica (aparentemente) muy efectiva para administrar la cátedra periodística.

A pesar de las polémicas suscitadas, es innegable que la existencia de los géneros periodísticos es necesaria [...]. Además, no debemos olvidar el papel que juega la clasificación de los géneros en el ámbito académico, ya 
que es difícil imaginar la enseñanza del Periodismo sin este instrumento pedagógico fundamental». (Fernández Parrat, 2001, edición electrónica).

Finalmente, de acuerdo con la tesis del profesor Lorenzo Gomis, la teoría de los géneros es el método mas seguro para la organización pedagógica de los estudios universitarios sobre periodismo». (Santamaría, 1991, p.109).

La teoría de los géneros periodísticos se asienta en la escuela de periodismo.

Entre una y otra se legalizan y certifican.

\section{Notas}

${ }^{1}$ Respecto a la Teoría de los géneros periodísticos, entre la enorme variedad de tratados y versiones, escogimos dos como referencias para este trabajo: el Curso general de redacción periodística de José Luis Martínez Albertos, en primer lugar (considerado por muchos tratadistas como el 'padre' de la teoría), y en segundo, los Géneros periodísticos de Gonzalo Martín Vivaldi, del cual anexamos un cuadro sinóptico al final de esta Presentación. La elección se fundamenta en el alto reconocimiento del que gozan las versiones de la teoría de estos autores, considerados clásicos.

La frase entre paréntesis es del autor. A partir de ahí, la idea podría reconstruirse como: Periodismo es información de actualidad concebida como creación literaria, cuyas modalidades son los géneros periodísticos.

${ }^{2}$ Recordemos la definición que se dio de teoría en la página 35 (nota al pie No. 4). Es en este sentido -el científico- que decimos que no existe una teoría literaria. Aunque reconocemos que existen intentos -desde diversos campos, incluso el artístico literario- por formalizar procedimientos o rutinas para la producción de textos.

${ }^{3} \mathrm{O}$ bien, que la Teoría de géneros es una especie de joker teórico, capaz de explicar la Literatura desde cualquier disciplina o punto de vista que se le asigne. Lo cual es, racionalmente, imposible.

${ }^{4}$ Hasta hoy, esta crítica de Croce cuenta como la más dura esgrimida contra la teoría clásica de los géneros literarios. El libro fue publicado por primera vez en italiano en el año de 1938. La edición que consultamos corresponde a la primera en español, de 1943.

${ }^{5}$ Recomendamos al lector repasar los fragmentos citados al principio de este numeral, o consultar algún manual de géneros periodísticos para comprobar la insuficiencia de la justificación del parecido entre las disciplinas.

${ }^{6}$ Otras posibles similitudes desde puntos de vista extrínsecos al tipo de producto y producción, es decir no esenciales al Periodismo y por ello no relevantes en su definición teórica no las discutimos aquí. Hablamos de, por ejemplo, el hecho de que haya escritores de Literatura haciendo prensa (también podría haber científicos u obreros de la construcción y esto no cambiaría el carácter del Periodismo; y sin embargo, este es uno de los lugares comunes favoritos para justificar una semejanza Periodismo-Literatura), o el hecho de que haya lectores que busquen en las lecturas del periódico las mismas emociones o cosmovisiones del mundo que hallan en la novela (otro aspecto subjetivo y extrínseco, pues hay, por igual, otros muchos lectores que abordan el periódico buscando información fáctica seca, y muchos artículos que ofreciendo información noticiosamente valiosa, no ofrecen visión poéticas alguna del mundo).

${ }^{7}$ Mariano Cebrián Herreros reconoce que este supuesto parecido entre Periodismo y Literatura en realidad sólo se refiere a su parecido con el modo narrativo de los tres que hay en Literatura:

- La tradición de la literatura oral o escrita desarrollado los géneros con enorme variedad. En la teoría de los géneros se han sistematizado tres núcleos: líricos, como expresión subjetiva de los sentimientos, ideas e interpretaciones del autor; narrativos, como exposición de relatos de hechos externos al autor; tradicionalmente el periodismo escrito ha sido enmarcado en este grupo, aunque no parece correcto del todo en la situación actual; y dramáticos, como plasmación del encuentro y choque de ideas, sentimientos, pasiones de personajes. Cada uno de estos tres grupos ha sufrido diversas vari

antes a lo largo de la historia». (Cebrián, 1992, p.12).

${ }^{8}$ Para que la analogía hubiese sido correcta en este sentido, en el que Periodismo se parece al modo narrativo de la Literatura pero no a los otros, tendríamos que haber adaptado al Periodismo una teoría

del modo narrativo. Al adaptar la Teoría de los géneros literarios completa, los tratadistas asimilan el Periodismo no a uno solo de los modos literarios (el narrativo), sino a los tres. Se asimila a la Literatura en su totalidad porque la teoría las incluye.

${ }^{9}$ En el ítem I.1 ejemplizábamos esta (relativa) irrelevancia de la dimensión lingüística del Periodismo (frente a las demás dimensiones/acciones constitutivas del hacer periodístico) señalando que, en Periodismo, se puede hablar de noticias muy buenas, independientemente de la calidad de la redacción, y de que ya se dice que un hecho es noticia mucho antes de que se lo redacte.

${ }^{10}$ Una precaución que hay que manejar siempre frente a la teoría, el caso de la Teoría de géneros es el de una teoría muy joven que se apeó de terminología vieja y prestigiosa («crónica» y «reportaje»

son palabras, incluso, previas al periodismo moderno); un intercambio que la beneficia notablemente en términos de estatus como supuesta hija y deudora de una tradición periodística centenaria.

${ }^{11}$ Más delante, en una cita de pié de página en el mismo texto, Santamaría escribe: En el libro de Manuel Grana, La Escuela de Periodismo [...] hay un par de referencias incidentales a los géneros periodísticos, sin ningún 
planteamiento global ni desarrollo posterior del concepto [...]. Parece lícito, por consiguiente, afirmar que el primer tratamiento sistemático de los géneros periodísticos fue llevado a cabo por el profesor Martínez Albertos en sus Géneros Periodísticos de 1961-62".

Así pues, José Luis Martínez Albertos no es sólo uno de los más importantes tratadistas y manualistas de la Teoría de los géneros periodísticos, sino también, su propio inventor o, al menos, el primero en dictar una cátedra y publicar un estudio sistemático de la aplicación de la noción de los géneros al Periodismo. Hasta hoy, también, el más acérrimo defensor de la teoría.

\section{Bibliografía}

Aguinaga, Enrique. 2002. El periodista en el umbral del siglo XXI. En Estudios sobre el mensaje periodístico No. 8, Editorial de la Universidad Complutense, pp. 157-170.

Bastenier, Miguel Ángel. 2001. El Blanco Móvil. Curso de Periodismo. Ediciones El País, España.

Bourdieu, Pierre. 1978. El oficio del sociólogo: Presupuestos Epistemológicos. Siglo Veintiuno Editores, México.

Cebrián Herreros, Mariano. 1992. Géneros informativos audiovisuales: Radio, Televisión, Periodismo Gráfico, Cine, Video. Editorial Ciencia 3 Distribución, Madrid.

Chillón, Albert. 1998. El «giro lingüístico» y su incidencia en el estudio de la comunicación periodística. En Anàlisi No. 22, Universitat Autónoma de Barcelona, Departament de Periodisme i de Ciències de la Comunicació, Barcelona.

Croce, Benedetto. 1943. Breviario de Estética. Cuatro lecciones, seguidas de dos ensayos y un apéndice. EspasaCalpe, Argentina.

Díaz Sotero, Paloma. S.f. Periodismo a la deriva. Edición electrónica: www.saladeprensa.org/art603 Ducrot, Víctor. 2005. «Objetividad o Subjetividad: mito del periodismo hegemónico. En Memorias del Seminario sobre la Intencionalidad Editorial. Edición electrónica: www.perio.unlp.edu.ar/intencionalidad/

Fernández Parrat, Sonia. 2001. El debate en torno a los géneros periodísticos en la prensa: nuevas propuestas de clasificación. En Zer: Revista de estudios de comunicación No. 11, País Vasco. Edición electrónica: http:// dialnet.unirioja.es/servlet/articulo?codigo $=802445$.

Gomis, Lorenzo. 1991. Teoría del periodismo. Cómo se forma el presente. Paidós, Barcelona.

Grijelmo, Alex. 1997. El estilo del periodista. Editorial Taurus, Madrid.

López Pan, Fernando. 2005. Aportaciones de la investigación periodística Española y nuevos desafíos. Periodística y nuevas generaciones, en Investigar sobre Periodismo II, Ponencia de la III Reunión Científica da Sociedade Española de Periodística, Edición electrónica: www.periodistica.es/imagenes/fotos/investigar_sobre_periodismo.pdf, pp. 4874.

Maigret, Eric. 2005. Sociología de la comunicación y de los medios. Fondo de Cultura Económica, Bogotá.

Martínez Albertos, José Luis. 1992. Curso general de redacción periodística. Lenguaje, estilos y géneros periodísticos en prensa, radio, televisión y cine. Editorial Paraninfo, Madrid.

CCC. 1995. La retórica en la enseñanza del periodismo, en Derecho y opinión No. 3, pp. 489-496.

CCC. 1990. Metodología para el conocimiento científico de la periodística, en Periodística, No. 2, Societat Catalana de Comunicació, Barcelona, pp. 45-51.

Santamaría Suárez, Luisa. 1994. Estado actual de la investigación sobre la teoría de los géneros periodísticos, en Estudios sobre el mensaje periodístico No. 1, España, pp. 37-56.

CCC. 1991. Géneros literarios y géneros periodísticos, en Periodística, Barcelona.

Van Dijk, Teun A. 1996. La noticia como discurso. Paidós Comunicación, Madrid.

Vivaldi, Gonzalo M. 1973. Géneros periodísticos. Reportaje, crónica, artículo (Análisis diferencial). Paraninfo, España.

Wolf, Mauro. 1984. Géneros y televisión. En Análisis, No. 5, Facultad de Ciencias de la Información, Universidad Autónoma de Barcelona.

\section{OTROS AUTORES IMPORTANTES, NO CITADOS}

Benjamin, Walter. 1991. El autor como productor, en Iluminaciones III, Taurus, Madrid.

Bunge, Mario. 1999a. Buscar la filosofía en las ciencias sociales. Siglo veintiuno editores, México.

CCC. 1999b. Las Ciencias Sociales en discusión, una perspectiva filosófica. Editorial Sudamericana, Buenos Aires.

CCC. 1996. Las Ciencia, su método y su filosofía. Panamericana Editorial, Bogotá.

Gans, Herbert J. 1980. Deciding what s news. A study of CBS Evening News, NBC Nightly News, Newsweek and Time. Vintage Books, New York.

Tuchman, Gaye. 1983. La producción de la noticia. Estudio sobre la construcción de la realidad. Gustavo Gili, Barcelona.

\section{Pàginas web:}

- www.webdelfénix.blogspot.com

- www.saladeprensa.org 